\title{
Multifunctionality in Agriculture. New Productive Paths in the Primary Sector
}

\author{
Rossella Bianchi \\ Department of Agro-Environmental and Territorial Sciences - DISAAT \\ University of Bari "Aldo Moro" \\ Italy
}

\begin{abstract}
This paper focuses on alternative productive paths in the primary sector in the framework of the transition from a farm business development model to a multifunctional paradigm. Analysis will be made of the connection between the rural world and tourism in the framework of European Union regional policies, along with the meaning of healthy local food as conceived by the rural tourist as a symbolic link to the culture and heritage of the holiday destination. Thus our focus will be concentrated on a special type of the tourist experience such as fishing tourism as managed in the Apulian coastal areas, in South Italy, a typology fully encompassed by multi-faceted activities related to the primary sector. The paper will point out how alternative rural tourist networks can enhance sustainable development paths especially in lagging areas within the framework of rural regeneration and endogenous dynamics as highlighted in local food system literature.
\end{abstract}

Keywords: Common Agricultural Policy, rural policies, multifunctionality, alternative local food systems, rural tourism, fishing-tourism.

\section{Introduction}

This paper aims to relate new development paths and new orientations in tourist demand and behaviour to the transition from a "productivist" and farm business development model - dominant until the 1970s within the framework of the Common Agricultural Policy (CAP) - to a multifunctional, environmentally sustainable and integrated paradigm in which the primary sector has opened up to become rural, thereby acquiring a systemic, diversified, alternative, and locally sustainable productive perspective (Bianchi 2011). In European Union (EU) countries, the debate on environmental sustainability, healthy food quality systems and gastronomic tourist typologies in rural areas also becomes possible because, on a macro-economic level, a new degree of attention in the direction of CAP goes beyond considerations strictly concerned with undifferentiated agro-food production (O’Neill 2014).

Accordingly, we will sketch out a brief evolutionary-historical outline of CAP orientation.

Analysis will then be made of both the connection between the rural world and tourism within the framework of emerging EU regional and rural policies, along with the meaning of healthy local food perceived by the rural tourist as a symbolic link to the culture and heritage of the holiday destination as highlighted in alternative local food system literature (Sims 2009).

Our focus will be concentrated on fishing tourism, as planned and managed in Apulian coastal areas, an innovative version of the tourism-leisure experience in South Italy, fully encompassed by multi-faceted activities related to the primary sector (Lane $1994[\mathrm{~b}]$ ).

Subsequently, this paper will attempt to point out how alternative rural tourist networks can enhance development paths related to sustainability in food consumption, all the while sustaining regional identities, culture and heritage in the framework of rural regeneration, productive diversification and endogenous development dynamics (Lane 1994 [a]; Sidali et Al. 2015).

\section{CAP and Food Security in the Seventies: Lights and Shadows}

At the end of the 1970s, the prevailing CAP model was showing clear signs of crisis (Viesti, Prota 2007). The goal of food security, set by the Treaty of Rome at the end of the 1950s, so hard pressed by the starvation and famine experienced in the Second World War, was successfully pursued (Fennel 1985). However this coincided with very severe financial, productive, environmental and social consequences (Priebe 1985). 
The almost exclusive implementation of the price and market policy bolstered increasingly intensive productive processes in the agricultural systems of the Member States with widespread use of chemicals and a high level of mechanisation and concentration of production activities in the flat, well-watered areas with a very high potential for economic and productive development (von Meyer 1983).

On the microeconomic level, the resulting imbalances involved, the allocation of inputs, productive patterns and disadvantages for small and medium sized farms (De Benedictis 1981); and, on a wider system level, environmental imbalances, distortions in international trade and the accumulation of huge food surpluses (von Meyer 1983).

Policies of export paybacks, price integration and guaranteed prices above the world market level created a situation of unsustainable "irrational subsidy", -"die Subventionierte Unvernunft" (Priebe 1985). Nor was the launch of a new structural policy in the 1970s able to harmonize different development levels, since it still encapsulated a farm- and sector-based concept of agricultural development and enhanced price and market orientation (Barbarella 1981).

\section{CAP and Multilateral World Trade: Pressures and New Orientations in the Eighties}

At the end of the 1980s, the political and international context changed along with the balance of power.

The process of market internationalization which began in the late 1960s was now fully developed and the perspective of a new globalized economy was emerging. New industrialized countries tried to enter into this context and put pressure on freer trade (Josling 1993). Furthermore, countries that were formerly excluded from western capitalism were now beginning to take part in commercial dynamics. During those years, the system of multilateral world trade changed very rapidly. Accordingly, a new approach to international trade and problems required an innovative set of rules (Josling 1993). At the international level, during the GATT negotiations in the framework of the Uruguay Round, there was some very strong pressure to liberalize international trade and thereby reduce agricultural prices to world market levels (OCDE, 1987). For the EEC it was a question of reducing its agricultural expenditure and giving a new balance to the price and market policy, restoring priority to the variable "price" in its meaning of orientation in the productive choices of farmers.

\section{From Agricultural to Rural. Towards a New Development Model}

Thus the time was ripe to bring a new degree of attention into the direction of CAP, going beyond considerations strictly concerned with production of agro-food surpluses. Regulations passed in the 1980s were aimed at addressing the problems of re-establishing market equilibrium and limiting the amount of surplus production through such principles as converting arable land, extensification and land set aside. However they actually introduced innovative issues of environmental protection, countryside preservation and support for agriculture in less-favoured areas, with the social and cultural aims of protecting the landscape and its resources. The differentiated specific regional problems were recognized, and a new rural development policy was approved for the less-favoured areas, emblematically indicated by the IMPs (Integrated Mediterranean Programmes, EEC Reg. no. 2088/85) with their systemic approach to development dynamics as well as Andriessen's 1985 Green Paper, which began to introduce a regional perspective for analysis of the problems of re-establishing social, economic and environmental equilibrium.

Among other options, here was the first explicit reference to encouragement of rural tourism as a form of diversification of farmers' incomes; the Single European Act with its unprecedented sensitivity towards economic and social cohesion (1986); and, above all, a new theoretical interpretation of the problems of the primary sector, which were carefully differentiated and analysed according to specific territorial features, contained in the fundamentally important planning document: "The Future of Rural Society" (1988).

\section{From Food Security to Food Safety. The Quality Turn in the CAP Orientation}

The political and cultural synthesis of the 1980s involved increased consideration of the environmental and rural aspects of regional development. These aspects began to influence economic issues and development processes and support the orientation of the reforms planned by the EEC. From the Reform of the Structural Funds in 1988 (EEC Reg. no. 2052/88) through the Mac Sharry Reform in 1992 and Agenda 2000 which introduced the socalled "second pillar" of the CAP specifically related to rural development policy (Loewe et Al., 2001), the process led to the Fischler Reform in 2003 (EC Reg. no. 1782/2003), which definitively downsized the old CAP. In this context, the framework used for analysis and interpretation of development problems was that of multifunctionality in a multidimensional perspective of the primary sector. 
This meant that agriculture could no longer limit its activities to the production of surpluses of qualitatively undifferentiated food products, but now had to provide healthy, quality foods, organoleptically intact, typical and specific according to the territorial area of origin, production techniques used and the adequate connections in the production chains (Brunori 2003). At the same time, agriculture also had to protect the landscape, safeguard natural resources and biodiversity, enhance cultural and eno-gastronomic traditions of the region and produce positive externalities for healthful environments and for society as a whole.

New productive dimensions have developed in the rural context, alternative to the traditional farm and sectoral models. Parks are increasingly important, as are nature reserves, nature paths, and agritourism or rural tourism, as it has been called since the 1980s in EEC documents and regulations (EEC Reg. no. 214/84). These alternatives have created space for culture and education, leisure and, more widely, for physical and mental re-integration in environmental contexts where the integrity of natural resources is protected, as well as the specific architectural, historical and cultural features of the rural areas (Bianchi 2011). In this way, even agro-food products acquire a series of intangible meanings linked to geographical specificity, and to the value given to the typical production methods belonging to the history of one place and not repeatable elsewhere (Brunori et Al. 2013).

\section{Sustainability both in Rural Development and Tourism: a Systemic Relationship}

Thus trajectories of agriculture or, more broadly, rural trajectories are intertwined with those of tourism, with systemic links in the foreground. Special interest deserves an Italian state law on tourism (Law no. 135/2001).

It pursues not only sustainable tourist development by protecting and enhancing environmental resources, as well as cultural heritage and local traditions but, even more importantly, by boosting strategic governance of rural areas and marginal economies in the context of integrated rural development. Moreover, the law highlights, in an innovative perspective, the value of the local eno-gastronomic supply, in addition to the cultural, architectural, environmental and historical-artistic heritage (art. 5, Law no. 135/2001) as features to characterize local tourist systems. Therefore alternative local food networks become the framework to improve lagging rural economies, enhance sustainable tourism, diversify farming activity and relieve fears about food safety (e.g. the Italian methanol wine scandal in 1986; British BSE in 1996 and the Foot and Mouth disease in 2001) in order to reestablish a systemic balance altered by intensive productive choices (O’Neill 2014).

It is in this way that alternative agro-food networks have been developed in rural areas. They are at the margins of intensive productive systems (Goodman, 2003); but at times coexisting with them, and are often complementary to them, as argued by O'Neill (2014), who underlines the complexity of productive and territorial relationships between alternative, local systems and conventional, intensive ones in his case-study on East Yorkshire, in the United Kingdom. On the basis of values such as embeddedness, trust and place, alternative agro-food networks launch a challenge to the effects of global competition (Goodman 2003) and create an alternative economic space antithetical to corporate power (Sayer 1997), neoliberal markets and resistant to agro-industrial food systems (Harris 2009).

\section{Local Food as a Relational Concept}

Focus here is on local food perceived by the tourist as tasty, fresh, "authentic" and healthy, a link to the place and culture of the holiday destination (Sims 2009).

Despite the concept in the literature of local food as not neat and unambiguous (O'Neill 2014), the iconic meaning it evokes embodies a powerful tool to enhance development processes (Sidali et Al. 2015).

Rebecca Sims's work on "food, place and authenticity" argues that tourist demand of local food and drinks opens up a market opportunity that can support alternative, local productive networks "that can encourage the development of sustainable agriculture, help conserve traditional farming landscapes and assist the local economy" (Sim 2009).

Local food thus acquires a relational meaning insofar as it boosts rural host community empowerment processes, on the one hand; and, on the other, strengthens in the rural post modern tourist the desire for authenticity, full immersion and identification with local culture and heritage and his (or her) social awareness in sustaining values of environmental resilience, economic sustainability and an anti-capitalistic attitude (Sidali et Al. 2015).

In so doing, beyond the tasty and healthy foodscape experience, rural gastronomic tourists also attain an intense sense of self and engagement with the values of the residents in the areas they visit (Bramwell 1994). 
This is particularly true in the case of fishing-tourism and the unique type of hospitality provided by professional fishermen, in Italian literally defined as ichthyo-tourism or ittitourism, though with no corresponding translation in English. The etymology of the word ichthyo dates back to ancient Greek and means fish itself. Namely they develop a special relationship between the host community, particularly fishermen, and the alternative rural tourist (Sidali et Al. 2015).

\section{Fishing- and ittitourism as alternative productive dimensions}

From a theoretical and empirical perspective, fishing- and ittitourism play an interesting and innovative role related to the multifunctionality of the fishery sector, sustainability in food consumption and responsible tourism. Fishing- and ittitourism are presented as eco-sustainable and environmentally friendly activities. They offer alternative sources of income for fishermen, with the aim of reducing the "fishing effort", giving balance to catch quotas and thereby protecting marine resources and their ecosystem. This is particularly important for protected marine reserves and their ecological stability. These are responsible tourism activities, put into practice with the aim of fishing correctly, all the while respecting environmental priorities, as requested by the EU in the framework of its structural development policies (Mantino 2008), and by the FAO, in its Code of Conduct for Responsible Fishing adopted in 1995.

Currently, on the national level, the most recent regulation for fishing-tourism is a ministerial decree, D.M. no. 4/2012, which lays out the general framework for the choices set up by the Italian Regions. However, since the 1990s, a state law has been passed (L. no. 165/1992) introducing the opportunity for professional fishermen to board outsiders on their vessels for touristic-leisure purposes in summer time. On the regional level, Marche (Marche Regional Law no. 11/2004); Abruzzo (Abruzzo Regional Law no. 23/2012); Emilia Romagna (Emilia Romagna Regional Law no. 228/2014) and Apulia (Apulia Regional Law no. 13/2015) have passed their specific regulation on fishing- and ittitourism.

It is interesting to note that other Regions such as Basilicata (Basilicata Regional Law no. 17/2005); Friuli Venezia Giulia (Friuli Venezia Giulia Regional Law no. 25/2007); Liguria (Liguria Regional Law no. 37/2007) and Veneto (Veneto Regional Law no. 28/2012) have regulated this matter along with the rules on agri-tourism, fully expressing the multidimensionality and multifunctionality of the primary sector. On the other hand, Tuscany (Tuscany Regional Law no. 56/2009) and Lazio (Lazio Regional Law no. 3/2010) pass their normative choices along with the rules on aquaculture and maritime fishing. Therefore, in the Italian juridical framework fishingtourism is seen as a new and complementary occupation directly related to the main activity of professional fishing in a full dimension of multifunctionality and environmental diversification. Thus, professional fishermen can host people (tourists, schoolchildren and anyone fascinated by sea life and culture) on their boats in order to offer them the opportunity to discover the maritime historical and cultural heritage.

Guests are involved in the crew's activities and allowed to do sport fishing; they discover maritime culture, traditional fishing techniques, coastal landscapes and stories told by fishermen as well as tasting freshly-caught fish cooked on board according to local traditional recipes. Ittitourism, on the other hand, consists of hospitality provided by professional fishermen in their own houses or places available to them, appropriately renovated in order to give guests a wide range of opportunities. Pride of places given to refreshments and food typical of traditional fishing, but there are also cultural, recreational and didactic activities aimed at highlighting local culture, environments and traditions. In this context it is also possible to set up fishing museums managed by fishermen and small shops selling food and drinks which derive from the local, eno-gastronomic heritage.

\section{The EU Leader Approach for Endogenous Local Development}

Apulia is a southern Italian region with a coastline of $865 \mathrm{~km}$ on both the Adriatic and Ionian Seas. Its natural environments, cultural heritage and wide eno-gastronomic variety make this region particularly interesting for alternative and niche tourism. In the framework of the EU regional policies carried out in order to promote a "bottom up" development, fishing-tourism initiatives on the Apulian coast have spread rapidly, even before the approval of its specific law by regional government.

This has happened in the context of Leader methodology.

Launched since the first structural funds programming cycle 1989-1993 as a Community Initiative specifically for rural areas, the Leader local development approach has been so successful that it has been integrated into the programming cycle 2007-2013 and become a specific mainstream axis of Rural Development Programmes set up on the regional level (Mantino 2008). 
Accordingly, Leader approach has been extended to urban and coastal areas and applied to the European Fisheries Fund (EFF); and recently for the programming cycle 2014-2020, to the European Maritime and Fisheries Fund (EMFF).

In Apulia, the six Fisheries Local Action Groups (FLAGs), set up in the programming cycle 2007-2013, have played a leading role as planning agencies in the promotion of integrated and "bottom up" development for coastal areas and fishing communities. They have financially supported, on the basis of strategic plans and operational programmes laid down by national authorities, development initiatives locally planned and managed to improve the marginal economy of coastal areas.

Fishing- and ittitourism, among the other activities (aquaculture, marketing, product traceability and labelling for fishing products), have been supported within the perspective of environmentally sustainable diversification and social regeneration of the local economy.

Through the EFF, FLAGs have financed the adjustment of the fleet for fishing-tourism and building improvements to implement initiatives of ittitourism (see our interview with dott. A. Settanni, Managing Director FLAG "Mare degli Ulivi", on $24^{\text {th }}$ July 2017).

This results in quite a dynamic context with examples of good practice as they have seen the involvement in the businesses of both lively cooperative organisations and family members, including young people who have implemented processes of renewal and modernization especially for marketing tools and social network use or smartphone application to communicate with buyers and tourists (www.readymedfish.eu).

\section{Local Food, Environmental Sustainability, Responsible Tourism}

Taken in this context, fishing- and ittitourism seem to be powerful tools to enhance integrated, sustainable development paths (Clark \& Chabrel 2007; Ilbery et Al. 2007), capable of activating positive dynamics for the integration of peripheral areas with the economy and society, with positive effects on the regional economy in terms of territorial competitiveness (Brunori 2003), cohesion of social networks (Di Iacovo 2003) and local ecological and environmental balance (van der Ploeg 2006).

This is shown by the schemes of processing, development and marketing of regional, typical and local agro-food products, which fishing- and ittitourism operators are obliged to use in their catering (at least 50\%, art.7, co.10 Apulian Regional Law no.13/2015) while fish products must be of their own production business or from local artisanal fisheries.

It is clear that local food plays an important role in gastronomic tourism: alternative tourists long for authentic experiences and are led there also through the consumption of local specialties. In the rural contest, the meaning is even more strongly felt: the desire to rediscover nature (Bramwell 1994), the search for freshness, taste and genuineness (Sim 2009), support for local producers and environmental awareness (Sidali et Al. 2015).

It is also interesting to consider direct selling by ittitourism operators, which is a way of enhancing short food supply chain, while at the same time sustaining healthy food systems with positive externalities on the environment. This sales strategy reduces the level of environmental pollution caused by long-distance transport and by the often complex commercial packaging necessary for large-scale retail distribution (Henke and Salvioni 2008).

\section{Conclusions}

The analysis focused on in this paper has attempted to highlight how the current re-orientation of the CAP has shaped a transition process from a "productivist" development model to a multifunctional, environmentally sustainable paradigm. This transition has witnessed a change in the analytical perspective, while the primary sector has acquired a new dimension not strictly connected to a farm-business meaning.

The rural dimension is multifaceted and new paths become productive in an alternative way.

The new development approach focuses on regional territories with their specific features, history, different development degrees, peculiar cultural heritage and specific productive vocations. The European Commission has launched its Reform of Structural Funds with high priority given to declining rural areas. Now that the price and market policy has been resized, it is possible to introduce issues such as environment, healthy food systems, rural tourism in a multifunctional perspective, with alternative food networks in the foreground. 
"Good, clean and fair" (Petrini 2005), the Slow Food's three principles, encapsulate features connected to health, safety and taste but also address issues such as public health, environmental awareness, ethics and social justice (Brunori et Al. 2013).

In this way, food is featured by tangible and immaterial attributes which define regional identities and involve the post-modern tourist, who experiences "a more authentic sense of self" (Sims 2009).

This paper has attempted to deepen the experiences of fishing- and ittitourism within this theoretical framework and has argued what a powerful role local healthy food systems can play in implementing the process of social regeneration, productive diversification and empowerment of local rural communities.

When it comes to promoting regional development models, two clear points stand out.

First: policy-makers, planners and entrepreneurs must focus on rural tourism and the concept of rurality in order to enhance sustainable development paths so as to launch long term endogenous development dynamics (Lane 1994 [a]).

Second: adequate marketing policies aimed to coordinate specific development options must be introduced. The present situation of competitiveness is above all based on the quality of regional healthy food systems and on crossbreeding processes between regional areas and their excellent products (Bramanti et Al. 1997).

This is a possible development path in order to differentiate marginal areas amid the leveling dynamics of the global economy.

\section{References}

Barbarella, C. 1981. La politica delle strutture agricole nella CEE: bilancio e prospettive, La Questione Agraria, n.1.

Bianchi, R. 2011. From agricultural to rural: Agritourism as a productive option. In K.L. Sidali, A. Spiller \& B. Schulze (eds.), Food, Agri-Culture and Tourism (56-71). Berlin-Heidelberg: Springer Verlag.

Bramanti, A. \& Maggioni, M.A. 1997. Struttura e dinamica dei sistemi produttivi territoriali: un'agenda di ricerca per l'economia regionale. In A. Bramanti \& M.A. Maggioni (eds.). La dinamica dei sistemi produttivi territoriali: teorie, tecniche, politiche. Milano: Franco Angeli, (Chapter 1).

Bramwell, B. 1994. Rural Tourism and Sustainable Rural Tourism?, Journal of Sustainable Tourism, 2: 1, 1- 6.

Brunori, G. 2003. Sistemi agricoli territoriali e competitività. In D. Casati (ed.) La competitività dei sistemi agricoli italiani, Atti del XXXVI convegno SIDEA, Milano: Franco Angeli.

Brunori, G., Malandrin, V., Rossi, A. 2013. Trade off or convergence? The role of food security in the evolution of food discourse in Italy, Journal of Rural Studies 2919 - 29.

Clark. N., Chabrel, M. 2007. Measuring integrated rural tourism, Tourism Geographies, 9, 371-386.

De Benedictis, M. 1981. Contraddizioni e conflitti di interesse nella politica agricola comune, La Questione Agraria, n.1.

Di Iacovo, F. 2003. (ed.). Lo sviluppo sociale nelle aree rurali. Milano: Franco Angeli.

Fennel, R. 1985. A Reconsideration of the Objectives of the Common Agricultural Policy, Journal of Common Market Studies, n. 3.

Goodman, D. 2003. The quality turn and alternative food practices: reflections and agenda (Editorial), Journal of Rural Studies $191-7$.

Harris, E. 2009. Neoliberal subjectivities or a politics of the possible? Reading for difference in alternative food networks. Area 41 (1), 3-16.

Henke, R \& Salvioni, C. 2008. Multifunzionalità in agricoltura: sviluppi teorici ed evidenze empiriche, Rivista di Politica Agraria, Anno LXIII, n. 1, Marzo.

Ilbery, B., Saxena, G., \& Kneafsey, M. 2007. Exploring tourists and gatekeepers' attitudes towards integrated rural tourism in the England-Wales border region. Tourism Geographies, 9, 441-468.

Josling, T. 1993. Dopo l'Uruguay round: l'agricoltura nel nuovo ordine mondiale, Rivista di Politica Agraria, anno XI, n.1.

Lane, B. 1994 [a]. What is rural tourism?, Journal of Sustainable Tourism, 2: 1, 7 - 21.

Lane, B. 1994 [b]. Sustainable rural tourism strategies: A tool for development and conservation, Journal of Sustainable Tourism, 2: 1, $102-111$. 
Mantino, F. 2008. Lo sviluppo rurale in Europa. Politiche, istituzioni e attori locali dagli anni '70 ad oggi. Milano: Edagricole, (Chapter 4).

Meyer, v. H. 1983. Wirkungslose Umweltpolitik-umweltwirksame Agrarpolitik. Ueberlegungen zum Verhaeltnis beider Politiken in der Europaischen Gemeinschaft, Zeitschrift fur Umweltpolitik, Heft 4.

OCDE 1987. National policies and agricultural trade. Paris.

O'Neill, K. 2014. Situating the alternative within the conventional - local food experiences from the East Riding of Yorkshire, UK, Journal of Rural Studies 35112 - 122.

Petrini, C. 2005. Buono, pulito e giusto. Principi di una nuova gastronomia. Torino: Einaudi.

Ploeg, J. D. Van Der. 2006. Oltre la modernizzazione. Processi di sviluppo rurale in Europa, Soveria Mannelli, Cosenza: Rubettino.

Priebe, H. 1985. Die Subventionierte Unvernunft. Berlin: Siedler.

Project funded by the European Union. Technical Report on the main constraints to the development of the multifunctionality of the fishery sector. [Online] Available: http://www.readymedfish.eu (accessed September 15, 2017).

Sayer, A. 1997. The dialectic of culture and economy. In R. Lee \& J. Willis (eds.), Geographies of Economies (16-26). London: Arnold.

Sidali, K.L., Kastenholz, E., Bianchi, R. 2015. Food tourism, niche markets and products in rural tourism: combining the intimacy model and the experience economy as a rural development strategy, Journal of Sustainable Tourism, vol.13 8-9 1179-1197.

Sims, R., 2009. Food, place and authenticity: local food and the sustainable tourism experience, Journal of Sustainable Tourism, 17(3), 321-336.

Viesti, G. and Prota, G. 2007. Le nuove politiche regionali dell'Unione Europea. Bologna: Il Mulino, (Chapter 4). 